Research Article

\title{
Identifying the Impact Factors of the Dynamic Strength of Mudded Intercalations during Cyclic Loading
}

\author{
Changbin Yan $\mathbb{D}^{1},{ }^{1}$ Xiao $\mathrm{Xu},{ }^{1}$ and Lei Huang $\mathbb{D}^{2}$ \\ ${ }^{1}$ School of Civil Engineering, Zhengzhou University, Zhengzhou, Henan 450001, China \\ ${ }^{2}$ Department of Engineering Geology and Geotechnical Engineering, Faculty of Engineering, China University of Geosciences, \\ Wuhan, Hubei 430074, China \\ Correspondence should be addressed to Lei Huang; huanglei@cug.edu.cn
}

Received 9 May 2018; Accepted 25 July 2018; Published 16 August 2018

Academic Editor: Gaofeng Zhao

Copyright ( $\odot 2018$ Changbin Yan et al. This is an open access article distributed under the Creative Commons Attribution License, which permits unrestricted use, distribution, and reproduction in any medium, provided the original work is properly cited.

\begin{abstract}
Despite reports on previous research associated with the dynamic strength of mudded intercalations during cyclic loading, a systematic investigation of the impact factors of this strength is still valuable. This work aimed at experimentally revealing the impact factors of the strength along with their impacts. The potential impact factors considered in this work include (i) water content, (ii) clay mineral composition, (iii) clay content, (iv) confining pressure, and (v) cyclic failure time. Specimens of mudded intercalations were collected from China and were remolded and prepared for a dynamic triaxial test under cyclic loads. The test results showed that the dynamic strength is impacted by water content (strongly), clay mineral composition (moderately), confining pressure (moderately), and cyclic failure time (weakly); no significant impact of clay content was detected. Moreover, the dynamic cohesion is correlated with clay mineral composition (strongly), water content (moderately), and cyclic failure time (weakly); no significant correlation with clay content or confining pressure was detected. Finally, the dynamic friction angle is correlated with water content (strongly), clay content (moderately), and cyclic failure time (weakly); no significant correlation with clay mineral composition or confining pressure was detected.
\end{abstract}

\section{Introduction}

The presence of mudded intercalations is known to deteriorate rock engineering. There exists a limited body of research on the dynamic strength associated with mudded intercalations during cyclic loading. Significant advances in this field include the report by Xue and Wang [1], who determined the dynamic strength indexes of mudded intercalations collected from the Xiaolangdi hydroproject using a cyclic simple shear test and a dynamic triaxial test. However, the potential impact of various factors (e.g., clay mineral composition, water content, grain gradation, and confining pressure) has not yet been reported. Despite numerous previous works investigating the impact factors of the dynamic strength of common fine-grain soils [2-11], little is known as to whether the same impacts occur in mudded intercalations, which are a special soil type whose main mineral composition is clay with breccia and rock fragments.
This work aims at experimentally identifying the impact factors of the dynamic strength of this special soil type and specifying their impacts. The potential impact factors considered in this work include (i) water content, $\omega$, (ii) clay mineral composition, $M$, (iii) clay content, $C$, (iv) confining pressure, $\sigma_{3}$, and (v) cyclic failure time, $N_{\mathrm{f}}$. Test specimens were collected from geological audits that service the large hydroproject near the Hukou waterfall of the Yellow River. Eighty-one groups of specimens with different values of the considered potential impact factors were remolded and prepared for dynamic triaxial testing under cyclic loads. The potential impacts of the factors were investigated and compared with those of related soils.

\section{Materials and Methods}

2.1. Testing Instrument and Specimens. Dynamic triaxial tests were performed on a DDS-70 electromagnetic vibration 


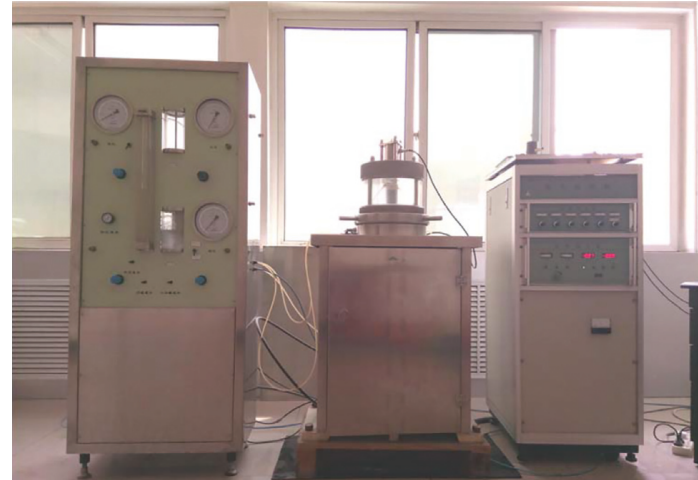

(a)

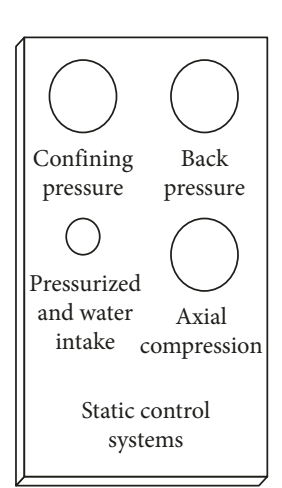

tatic control

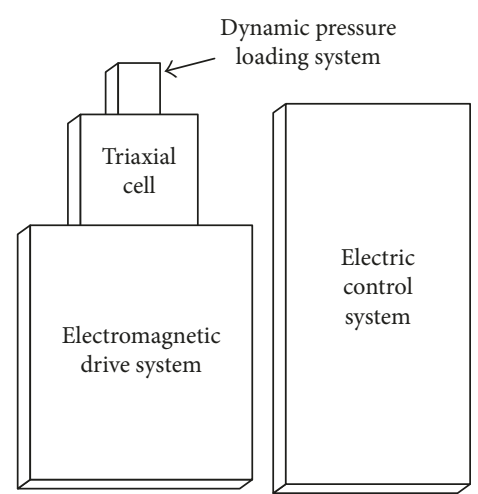

(b)

FIgure 1: DDS-70 dynamic triaxial test apparatus: (a) view; (b) schematic diagram.

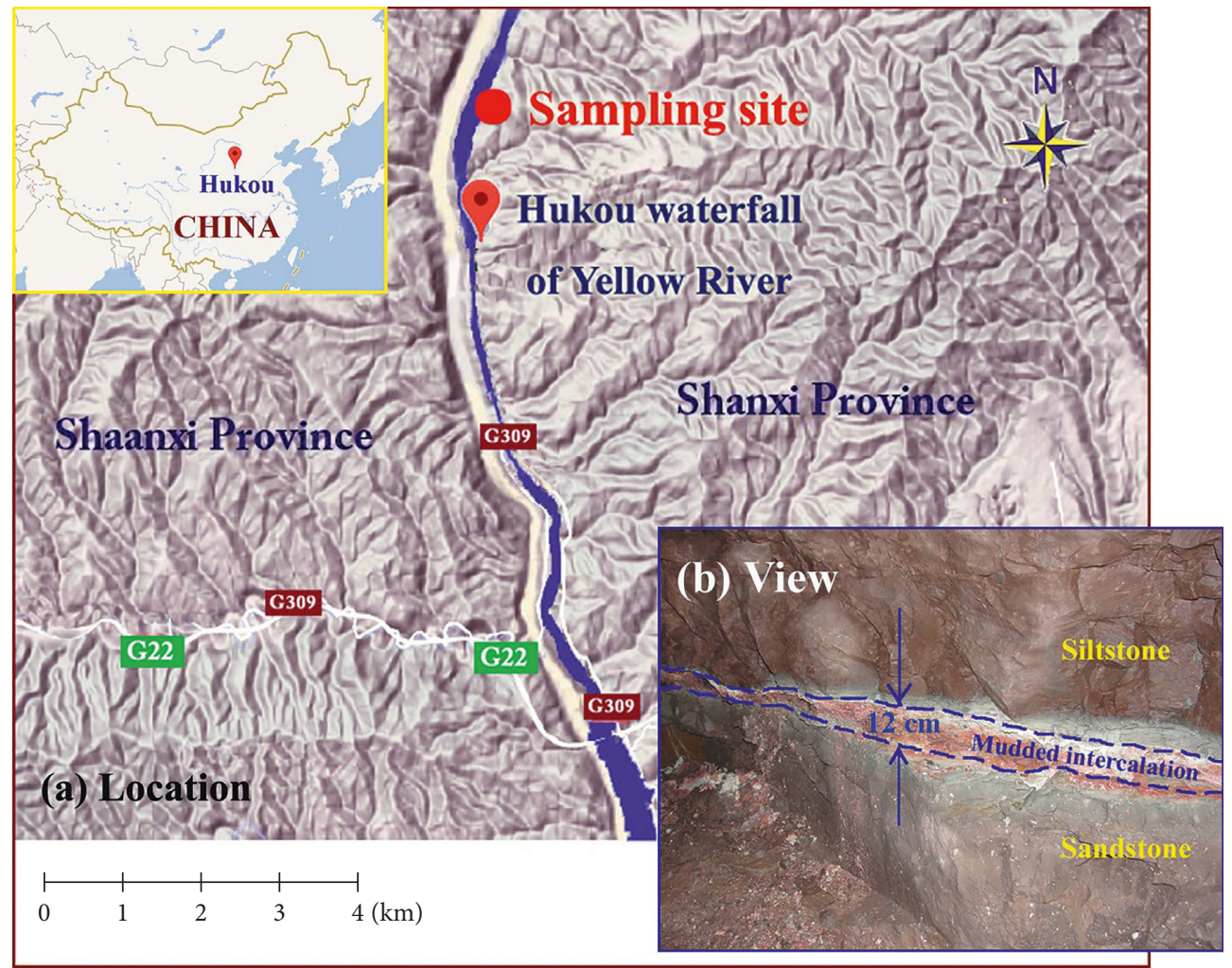

FIGURE 2: Specimen sampling sites: (a) location; (b) view.

triaxial apparatus, as shown in Figure 1. The maximum allowable axial displacement and maximum allowable axial force are $20 \mathrm{~mm}$ and $1370 \mathrm{~N}$, respectively. The allowable frequency range is between $0 \mathrm{~Hz}$ and $10 \mathrm{~Hz}$.

The specimens were sampled from a geological audit of a large hydroproject (location shown in Figure 2) and remolded into a standard size (shown in Figure 3 ). To investigate the potential impacts of (i) water content $(\omega)$, (ii) clay mineral composition $(M)$, and (iii) clay content $(C)$ on the dynamic strength and its indexes, specimens with various physical properties, as listed in Table 1, were collected. The grading results of the particle sizes are shown in Figure 4.
2.2. Test Procedure. The test was conducted a total of 81 times. As listed in Table 1, there are 9 groups of remolded specimens for each type of main clay mineral composition. For each group of remolded specimens, 3 levels of confining pressure $\left(\sigma_{3}\right)$ are applied: $100 \mathrm{kPa}, 200 \mathrm{kPa}$, and $300 \mathrm{kPa}$. For each level of confining pressure, it is necessary to apply different axial dynamic loads $\left(\sigma_{\mathrm{de}}\right)$ to the 3 specimens.

The loading process is shown in Figure 5. An equivalent sinusoidal wave with a frequency $(f)$ of $1 \mathrm{~Hz}$ is used as the axial dynamic load, and the consolidation stress ratio $\left(K_{\mathrm{c}}\right)$ is set at 1 . The test procedure is shown in Figure 6.

In general, under isobaric pressure consolidation, typical soils can be expected to fail once the strain reaches 


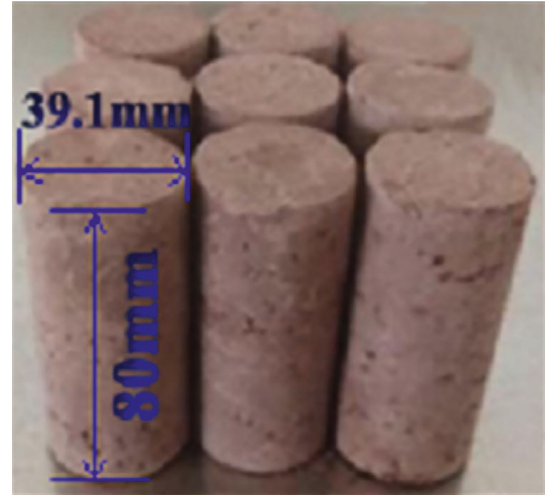

(a)

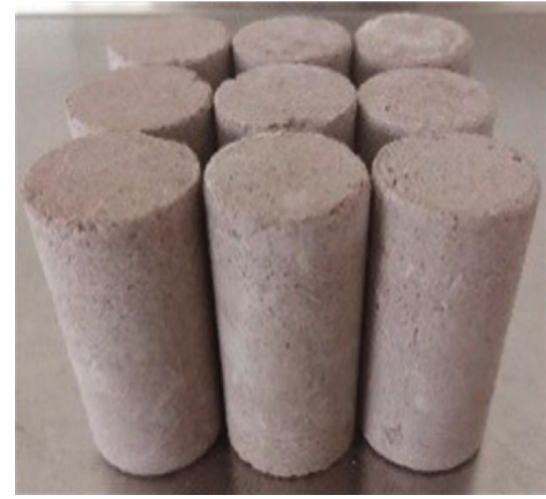

(b)

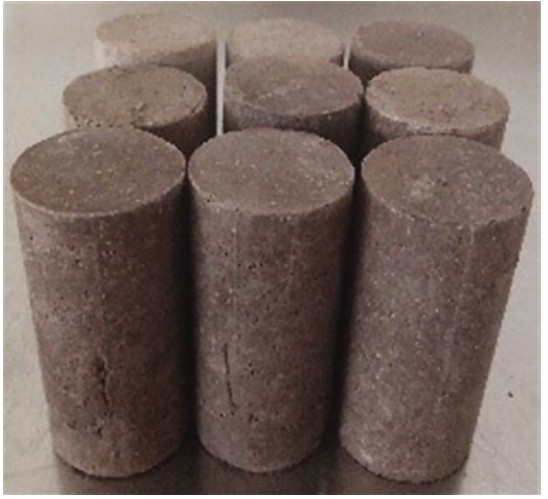

(c)

Figure 3: Specimens after remolding: (a) Groups 1 3; (b) Groups 4 6; (c) Groups 7 9.

TABle 1: Physical properties of remolded specimens.

\begin{tabular}{|c|c|c|c|c|c|}
\hline $\begin{array}{l}\text { Group } \\
\text { number }\end{array}$ & Sampling site & Main clay mineral composition, $M$ & $\begin{array}{c}\text { Clay content, } \\
C(\%)\end{array}$ & Dry density $\left(\mathrm{g} / \mathrm{cm}^{3}\right)$ & $\begin{array}{c}\text { Water content, } \\
\omega(\%) \\
\end{array}$ \\
\hline 1 & & & & & 11.3 \\
\hline 2 & PD207 and PD302 & Mixed montmorillonite/illite & 29.2 & 1.9 & 15.1 \\
\hline 3 & & & & & 18.7 \\
\hline 4 & & & & & 11.3 \\
\hline 5 & PD302 & Illite & 21.0 & 1.9 & 15.1 \\
\hline 6 & & & & & 18.7 \\
\hline 7 & & & & & 11.3 \\
\hline 8 & PD207 and PD215 & Kaolinite & 48.8 & 1.9 & 15.1 \\
\hline 9 & & & & & 18.7 \\
\hline
\end{tabular}

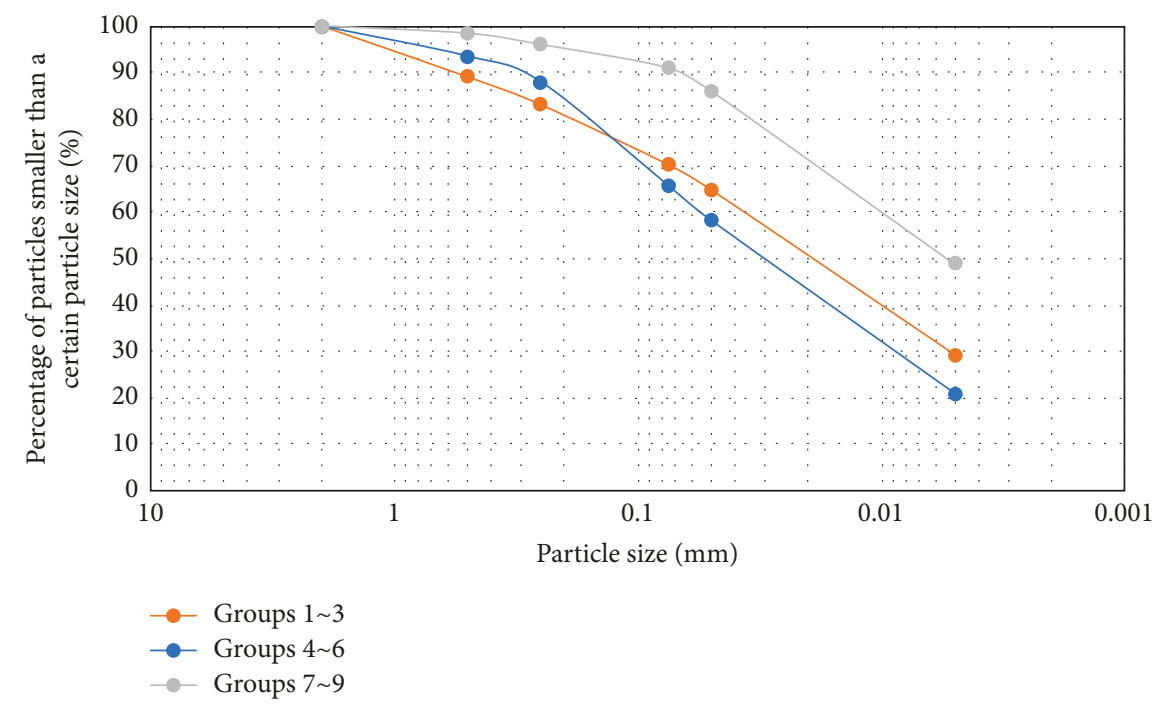

FIGURE 4: Grading of the particle sizes.

$5 \%[3,4]$. However, the strength of the mudded intercalations tends to be smaller in comparison with common soils. As a result, under cyclic loading, the initial strain values are larger and the development of damage is slower. This $5 \%$ strain failure criterion is therefore not quite suitable for mudded intercalations. Instead, the $10 \%$ strain failure criterion [12] is more reasonable and was therefore adopted in the test.

\section{Results}

3.1. Properties of Dynamic Strength, $\tau_{d f}$. The cyclic time corresponding to the time point at which the cumulative strain $\left(\varepsilon_{d}\right)$ meets the prescriptive strain failure criterion is defined as the cyclic failure time $\left(N_{\mathrm{f}}\right)$. The dynamic shear stress occurring when the cycle number $(N)$ meets $N_{\mathrm{f}}$ is defined as the dynamic strength $\left(\tau_{\mathrm{df}}\right)$. 


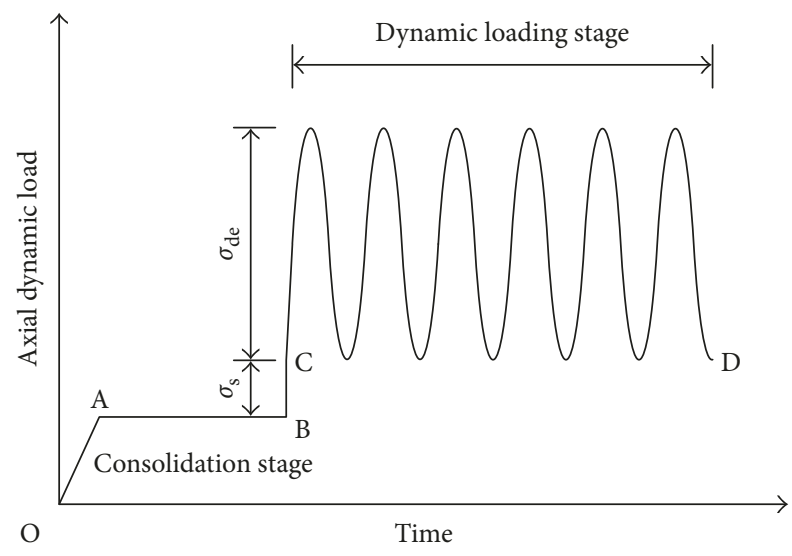

FIGURE 5: Loading process.

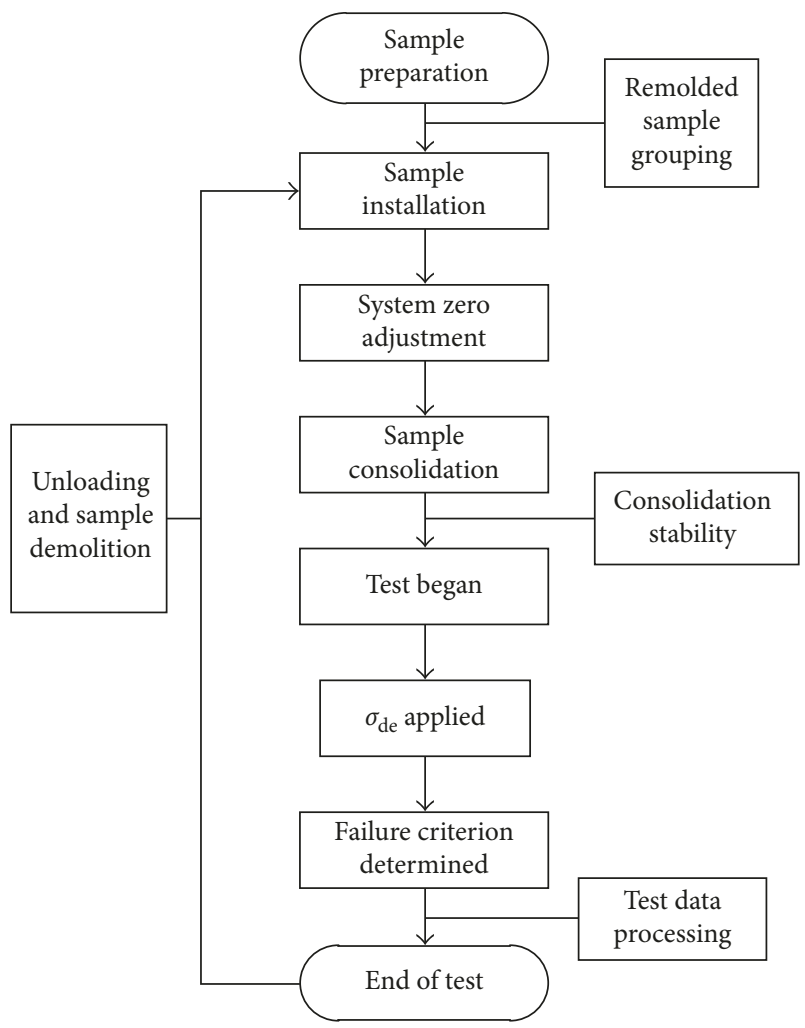

Figure 6: Test procedure.

Figure 7 shows the relationship between $\varepsilon_{d}$ and $N$. $\varepsilon_{d}$ initially increases slowly with $N$, followed by a more rapid increase. This trend is not affected by the confining pressure, $\sigma_{3}$. Moreover, the increase of $\sigma_{3}$ and the cyclic stress ratio $\left(r_{d} ; r_{d}=\sigma_{\mathrm{de}} / \sigma_{3}\right)$ contribute to an increased initial cumulative strain value $\left(\varepsilon_{0}\right)$, an increased rate of $\varepsilon_{d}$, and a decreased $N_{\mathrm{f}}$.

The relationship between $\tau_{\mathrm{df}}$ and $N_{\mathrm{f}}$ is shown in Figure 8.

As shown in Figure $8, \tau_{\mathrm{df}}$ decreases with $N_{\mathrm{f}}$. Their relationship is fitted as

$$
\tau_{\mathrm{df}}=A N_{\mathrm{f}}^{-B},
$$

where $A$ and $B$ are fitted coefficients.

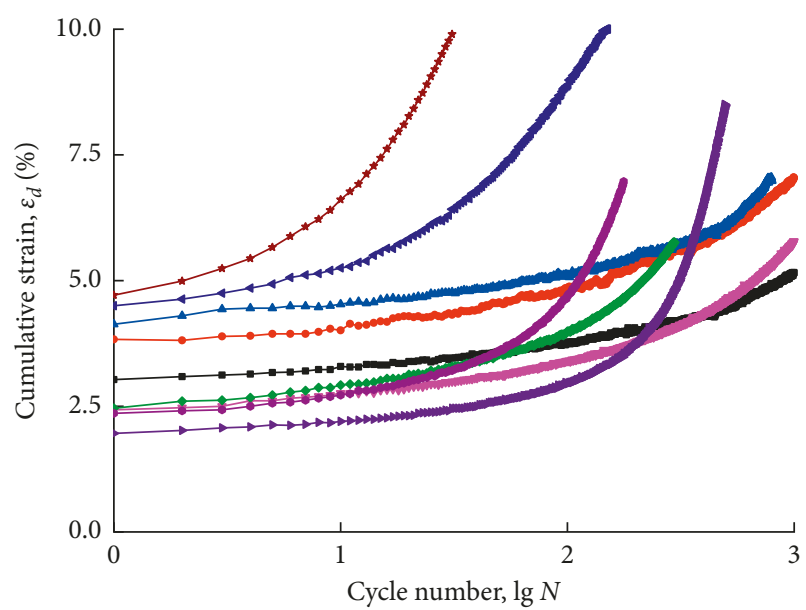

Figure 7: Cumulative strain, $\varepsilon_{d}$, versus cycle number, $N$ (no. 8 remolded specimens).

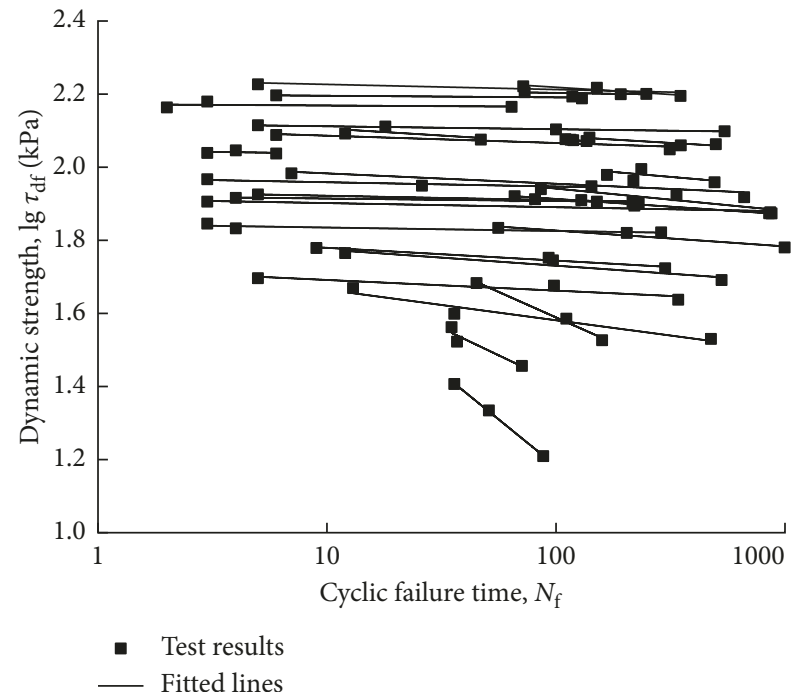

Figure 8: Relationship between $\tau_{\mathrm{df}}$ and $N_{\mathrm{f}}$.

The obtained values of $A$ and $B$ are listed in Table 2. More than $63 \%$ of the $R^{2}$ values are greater than 0.7 , indicating a good fit.

An orthogonal test [3] (Table 3) shows that $A$ is impacted by $M$ (strongly), $\sigma_{3}$ (moderately, positive), and $\omega$ (weakly, initially negative and then positive). The $B$ is impacted by $\omega$ (strongly, positive), $M$ (slightly), and $\sigma_{3}$ (weakly, negative).

3.2. Impact Factors of Dynamic Strength, $\tau_{d f}$. The orthogonal test results show that $\tau_{\mathrm{df}}$ is correlated with $\omega$ (strongly), $M$, $\sigma_{3}$ (moderately), and $N_{\mathrm{f}}$ (weakly). Figure 9 shows $\tau_{\mathrm{df}} \sim N_{\mathrm{f}}$ under different conditions, while Figure 10 shows the impact of factors on $\tau_{\mathrm{df}}$, where the ordinate is $k_{j m} / k_{j m \max }$ and the abscissa is the impact of the factors.

3.2.1. Impact Factor I: Water Content, $\omega$. Figure 9(a) indicates that $\tau_{\mathrm{df}}$ decreases with $\omega$ when the main clay mineral composition is kaolinite and $\sigma_{3}$ is $200 \mathrm{kPa}$. In comparison, 
TABLE 2: Obtained values of $A$ and $B$.

\begin{tabular}{|c|c|c|c|}
\hline Group number & Confining pressure, $\sigma_{3}(\mathrm{kPa})$ & $A$ & $B\left(10^{-2}\right)$ \\
\hline \multirow{3}{*}{1} & 100 & 6.324 & 0.947 \\
\hline & 200 & 7.736 & 0.817 \\
\hline & 300 & 8.779 & 0.353 \\
\hline \multirow{3}{*}{2} & 100 & 6.138 & 3.498 \\
\hline & 200 & 7.175 & 1.174 \\
\hline & 300 & 8.533 & 3.822 \\
\hline \multirow{3}{*}{3} & 100 & 9.035 & 50.931 \\
\hline & 200 & 7.441 & 29.820 \\
\hline & 300 & 8.554 & 27.871 \\
\hline \multirow{3}{*}{4} & 100 & 6.774 & 1.127 \\
\hline & 200 & 8.899 & 5.376 \\
\hline & 300 & 9.236 & 0.989 \\
\hline \multirow{3}{*}{5} & 100 & 6.916 & 1.195 \\
\hline & 200 & 8.332 & 0.807 \\
\hline & 300 & 9.947 & 3.927 \\
\hline \multirow{3}{*}{6} & 100 & 6.776 & 4.332 \\
\hline & 200 & 7.869 & 6.066 \\
\hline & 300 & 8.231 & 5.375 \\
\hline \multirow{3}{*}{7} & 100 & 6.828 & 0.678 \\
\hline & 200 & 8.660 & 3.690 \\
\hline & 300 & 9.025 & 0.444 \\
\hline \multirow{3}{*}{8} & 100 & 7.372 & 4.224 \\
\hline & 200 & 7.474 & 2.838 \\
\hline & 300 & 8.217 & 1.994 \\
\hline \multirow{3}{*}{9} & 100 & 5.746 & 8.360 \\
\hline & 200 & 5.588 & 2.914 \\
\hline & 300 & 6.164 & 4.403 \\
\hline
\end{tabular}

TABLE 3: Orthogonal test results. $K_{j m}$ is the sum of the parameters for the row level $m$ repeated tests for the $j$ line factor. $k_{j m}$ is the average value of the parameters. $R_{j}$ is the range (i.e., the difference between the maximum and minimum) of $k_{j m} \cdot \eta_{j}=\left(R_{j} / \sum \mathrm{R}_{\mathrm{j}}\right) \times 100 \%$, such that $\eta_{j}$ represents the contribution of factor $j$ to $A$ or $B$.

\begin{tabular}{cccccccc}
\hline$A$ & $M$ & $\omega(\%)$ & $\sigma_{3}(\mathrm{kPa})$ & $B$ & $M$ & $\omega(\%)$ & $\sigma_{3}(\mathrm{kPa})$ \\
\hline$K_{j 1}$ & 25.304 & 23.800 & 22.779 & $K_{j 1}$ & 55.570 & 2.484 & 52.804 \\
$K_{j 2}$ & 24.021 & 22.923 & 23.079 & $K_{j 2}$ & 8.250 & 7.855 & 9.721 \\
$K_{j 3}$ & 20.466 & 23.068 & 23.933 & $K_{j 3}$ & 7.919 & 61.400 & 9.214 \\
$k_{j 1}$ & 8.435 & 7.933 & 7.593 & $k_{j 1}$ & 18.523 & 0.828 & 17.601 \\
$k_{j 2}$ & 8.007 & 7.641 & 7.693 & $k_{j 2}$ & 2.750 & 2.618 & 3.240 \\
$k_{j 3}$ & 6.822 & 7.689 & 7.978 & $k_{j 3}$ & 2.640 & 20.467 & 3.071 \\
$R_{j}$ & 1.613 & 0.292 & 0.385 & $R_{j}$ & 15.773 & 19.639 & 14.530 \\
$\eta_{j}$ & $70.44 \%$ & $12.76 \%$ & $16.80 \%$ & $\eta_{j}$ & $31.58 \%$ & $39.32 \%$ & $29.09 \%$ \\
\hline
\end{tabular}

$\tau_{\text {df }}$ initially increases slightly with $\omega$ but then decreases (Figure 10(a)). This phenomenon may be attributed to the critical water content, $\omega_{0}$. That is, for an $\omega$ value smaller than $\omega_{0}, \tau_{\mathrm{df}}$ increases with $\omega$, whereas it decreases for an $\omega$ value greater than $\omega_{0}$. This behavior agrees with findings for common soil reported in $[13,14]$.

3.2.2. Impact Factor II: Confining Pressure, $\sigma_{3}$. Figure 9(b) shows that $\tau_{\mathrm{df}}$ increases with $\sigma_{3}$, where $\omega$ is $15.1 \%$ and the main clay mineral composition is mixed montmorillonite/ illite. A similar result is exhibited in Figure 10(c). These results are consistent with those of ordinary soils, as demonstrated in $[4,15,16]$.

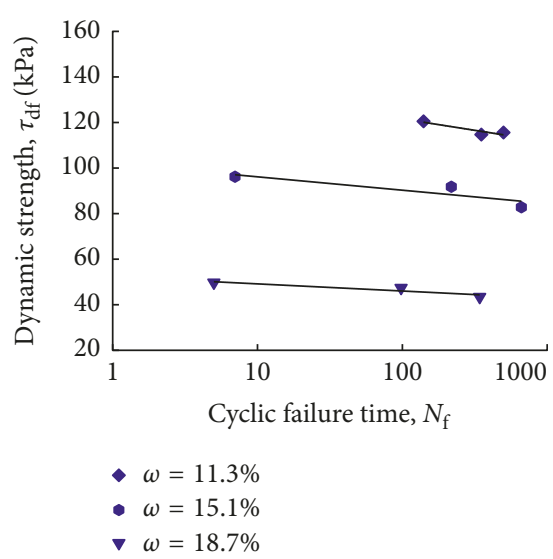

(a)

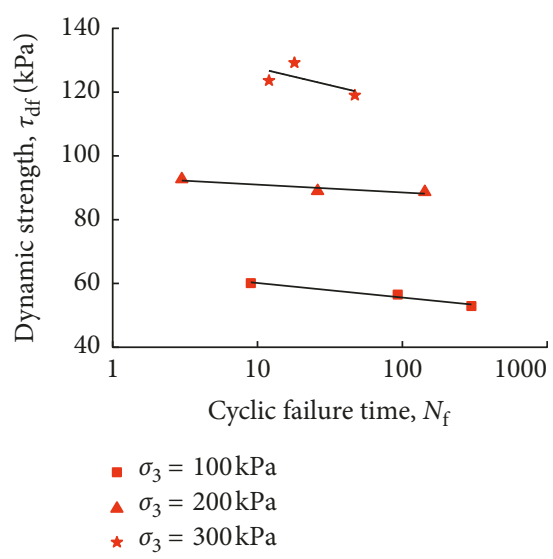

(b)

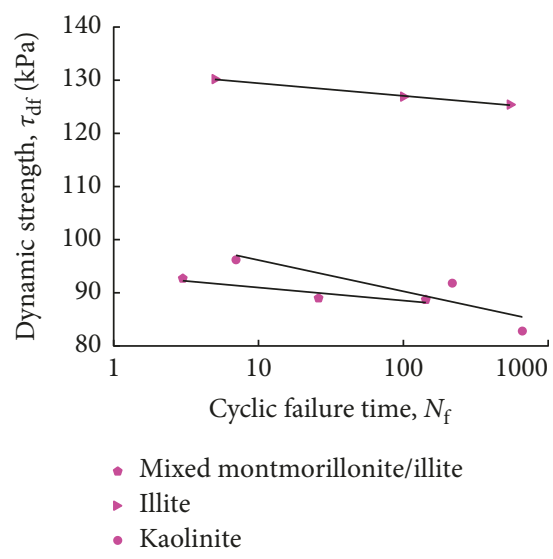

(c)

FIgURE 9: $\tau_{\mathrm{df}}$ versus $N_{\mathrm{f}}$ for different cases of (a) $\omega$, (b) $\sigma_{3}$, and (c) $M$.

3.2.3. Impact Factor III: Clay Mineral Composition, $M$. Figure $9(\mathrm{c})$ shows $\tau_{\mathrm{df}}$ when the main clay mineral composition is primarily illite. A similar result is exhibited in Figure 10(b). This result differs from that revealed in [17-19].

3.2.4. Impact Factor IV: Cyclic Failure Time, $N_{f}$. Figure 8 shows that $\tau_{\mathrm{df}}$ decreases with $N_{\mathrm{f}}$. A different result is presented in Figure $10(\mathrm{~d})$, which shows that $\tau_{\mathrm{df}}$ does not always decrease with $N_{\mathrm{f}}$. The difference is likely caused by 


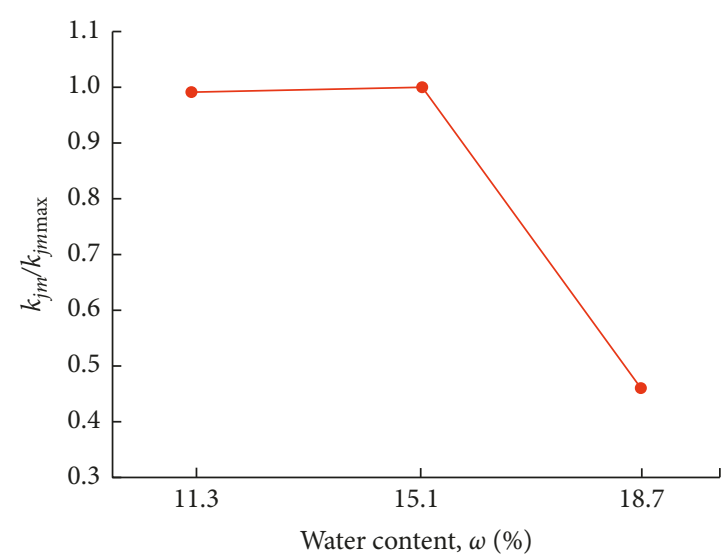

(a)

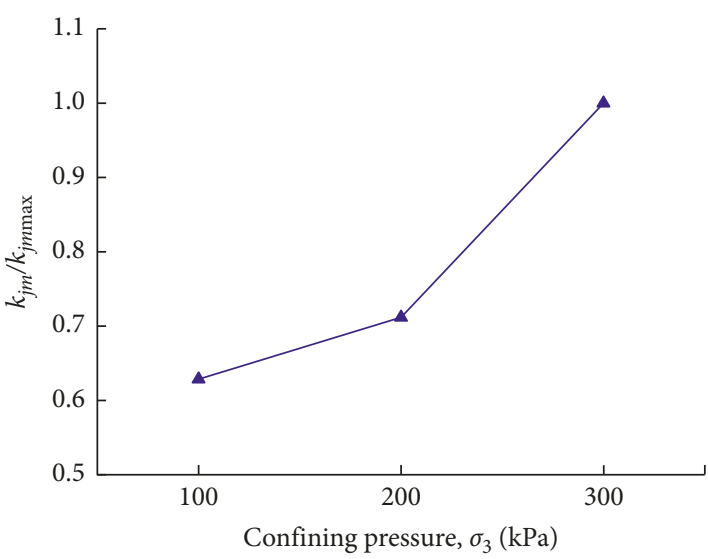

(c)

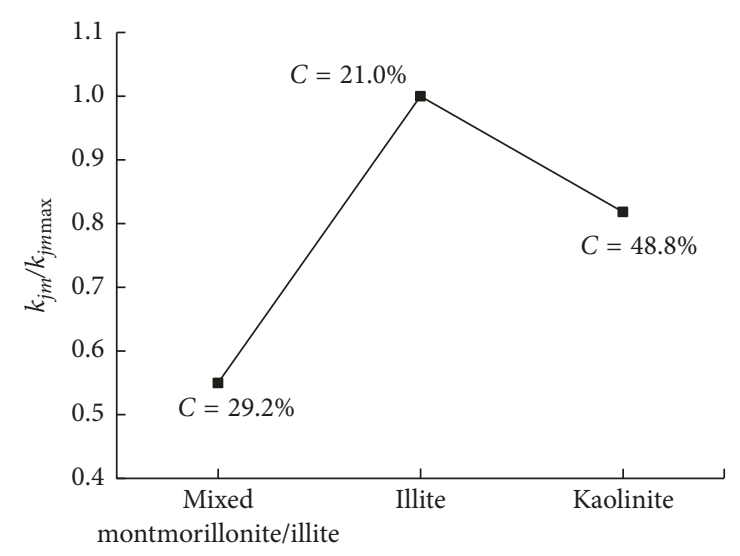

(b)

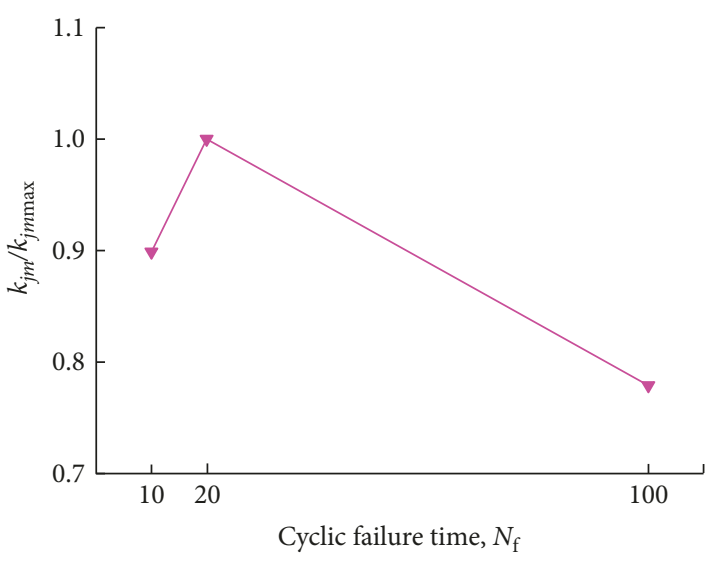

(d)

FIgURE 10: Factor effects on $\tau_{\mathrm{df} .} k_{j m} / k_{j m \max }$ versus (a) $\omega$, (b) $M$, (c) $\sigma_{3}$, and (d) $N_{\mathrm{f}}$.

TABLe 4: Values of $C_{\mathrm{d}}$ and $\varphi_{\mathrm{d}}$ determined for the case of $N_{\mathrm{f}}=20$.

\begin{tabular}{lcc}
\hline Group number & $C_{\mathrm{d}}(\mathrm{kPa})$ & $\varphi_{\mathrm{d}}\left({ }^{\circ}\right)$ \\
\hline 1 & 11.4 & 9.6 \\
2 & 9.8 & 8.3 \\
3 & 8.0 & 3.6 \\
4 & 15.3 & 10.2 \\
5 & 16.5 & 10.1 \\
6 & 20.0 & 6.6 \\
7 & 19.1 & 9.2 \\
8 & 31.3 & 4.3 \\
9 & 17.0 & 2.0 \\
\hline
\end{tabular}

a variation in the compactness. That is, the compactness rises with $N_{\mathrm{f}}$, resulting in an increase in $\tau_{\mathrm{df}}$ [5].

3.3. Impact Factors of the Dynamic Strength Indexes, $C_{d}$ and $\varphi_{d}$. The dynamic strength indexes, $C_{\mathrm{d}}$ and $\varphi_{\mathrm{d}}$, are determined as follows: first, $\tau_{\mathrm{df}}$ is evaluated based on Seed's [20] equivalent cyclic failure time. Then, using $\tau_{\mathrm{df}}$, Mohr's stress circle can be obtained, and $C_{\mathrm{d}}$ and $\varphi_{\mathrm{d}}$ are consequently determined (see results in Table 4). As shown in Table $4, C_{\mathrm{d}}$ is closely related to the clay mineral composition, which has a contribution rate of $67.23 \% . \varphi_{\mathrm{d}}$ is closely related to $\omega$. Figures 11 and 12 show the impacts of various factors on $C_{\mathrm{d}}$ and $\varphi_{\mathrm{d}}$.
3.3.1. Impact Factor I: Water Content, $\omega$. As shown in Figure $11(\mathrm{a}), C_{\mathrm{d}}$ increases with $\omega$ when $\omega$ is less than $\omega_{0}$, and vice versa for $\omega$ greater than $\omega_{0} . \varphi_{\mathrm{d}}$ decreases with $\omega$ (Figure 12(a)).

3.3.2. Impact Factor II: Clay Mineral Composition, $M$, and Clay Content, C. Figure 11(b) shows that $C_{\mathrm{d}}$ is affected by the clay mineral composition. Specifically, the $C_{\mathrm{d}}$ values for illite as the main clay mineral composition are greater than those with mixed montmorillonite/illite but lower than those with kaolinite. Moreover, $\varphi_{\mathrm{d}}$ decreases with $C$ (Figure 12(b)).

3.3.3. Impact Factor III: Cyclic Failure Time, $N_{f}$ Figure 11(c) shows that $C_{\mathrm{d}}$ initially increases slightly with $N_{\mathrm{f}}$ and then decreases. A similar variation in $\varphi_{\mathrm{d}}$ is observed (Figure 12(c)).

3.4. Comparison with Other Soils. The dynamic strength indexes of the mudded intercalations are compared to those of soils from other sites, as documented in [1, 21-23]. The test results are shown in Figure 13.

Figure 13 compares the upper and lower limit values of the dynamic strength for samples from various sites. 


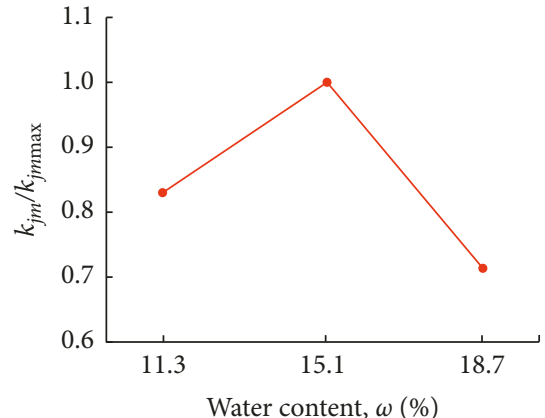

(a)

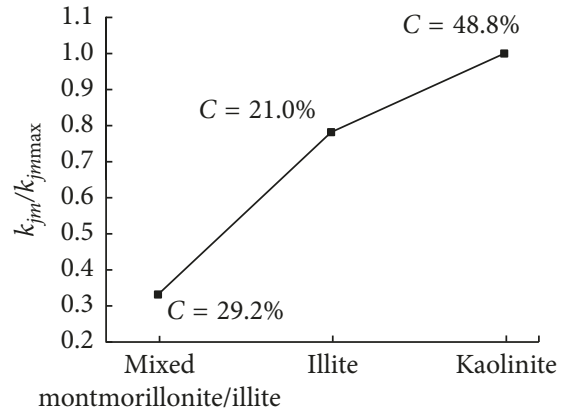

(b)

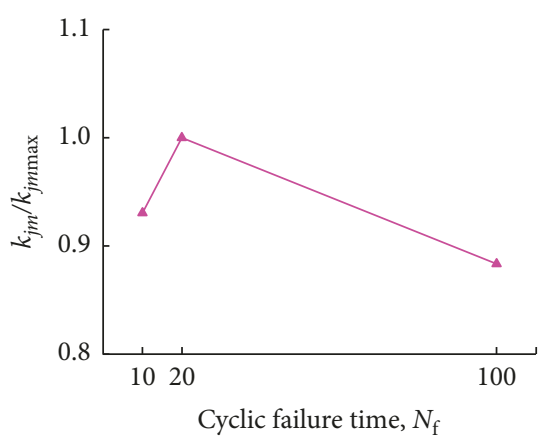

(c)

Figure 11: Factor effects on $C_{\mathrm{d}} \cdot k_{j m} / k_{\text {jmmax }}$ versus (a) $\omega$, (b) $M$, and (c) $N_{\mathrm{f}}$.

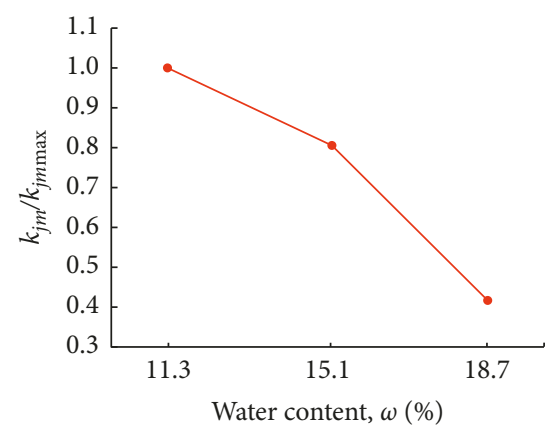

(a)

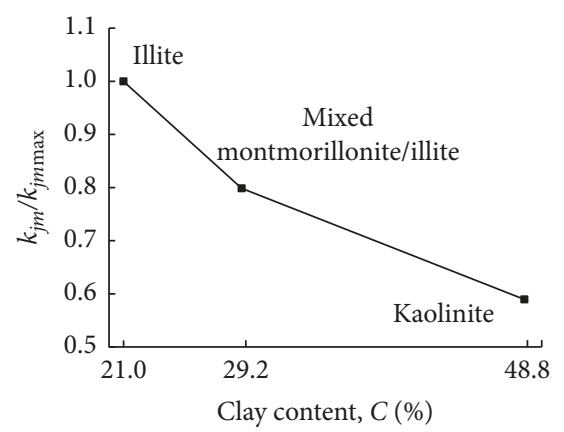

(b)

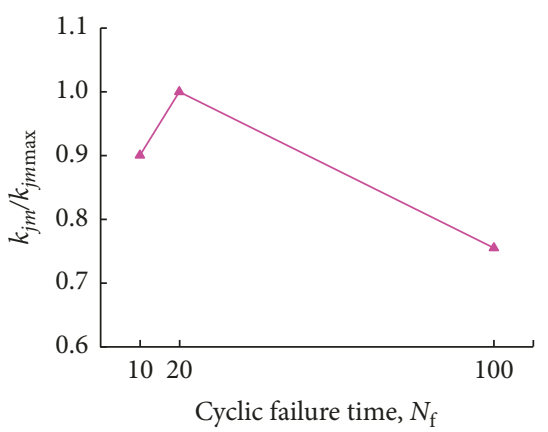

(c)

FIGURE 12: Factor effects on $\varphi_{\mathrm{d}} \cdot k_{j m} / k_{j m \max }$ versus (a) $\omega$, (b) $M$, and (c) $N_{\mathrm{f}}$.

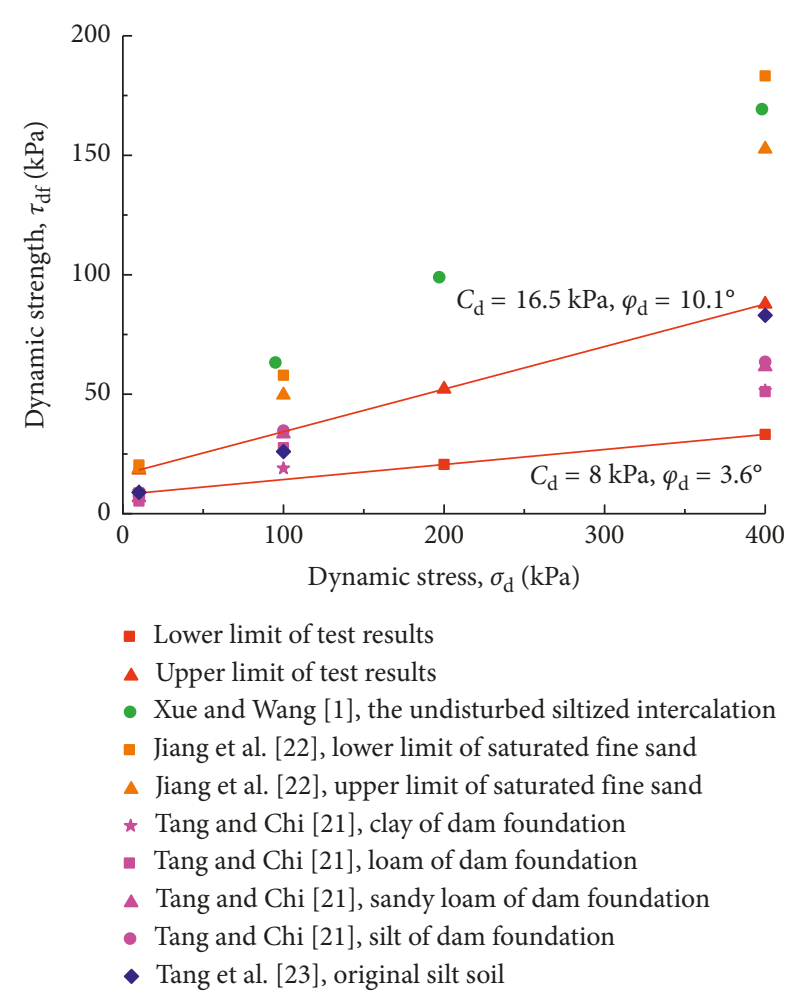

Figure 13: Dynamic strength limit of mudded intercalations.
The comparison shows that the dynamic strength of mudded intercalations is generally smaller than that of loess, silt, clay, and other common soils. Possible reasons for this phenomenon are as follows: (a) a structural disturbance due to remolding leads to a significant decrease in the dynamic strength; (b) the mudded intercalations tested in this work are partially composed of mixed montmorillonite/illite, which have relatively low strengths; and (c) the clay content varies depending upon the site, resulting in differences in the dynamic strength.

\section{Discussion}

Previous literature has concluded that the $\tau_{\mathrm{df}}$ of mudded intercalations with kaolinite is higher than that for illite [17-19]. However, a different result was observed here; namely, the former is lower than the latter (Figure 9(c)). As a factor that accounts for the disparity between the two results, the clay content of the mudded intercalations in this study corresponding to illite is only $21.0 \%$. This is much lower than the clay content of kaolinite, which reaches $48.8 \%$. The greater the clay content, the smaller the dynamic strength [24-26]. A similar relationship is observed for the dynamic strength indexes of the mudded intercalations, as shown in Figure 11(b). As the mechanical properties of the main mineral composition improve, $C_{\mathrm{d}}$ of the mudded 
intercalations increases. Moreover, the impact of the clay content on $\varphi_{\mathrm{d}}$ is more significant, as shown in Figure 12(b), where $\varphi_{\mathrm{d}}$ decreases with clay content. The clay mineral composition and clay content constitute two primary impact factors for the dynamic strength indexes of mudded intercalations, which are different from common soils.

\section{Conclusion}

The impacts of various factors on the mudded intercalation dynamic strength, including (i) clay mineral composition, (ii) water content, (iii) clay content, (iv) confining pressure, and (v) cyclic failure time, were investigated. The following conclusions were drawn:

(1) A greater confining pressure and cyclic stress ratio contribute to lower cyclic failure times.

(2) The dynamic strength is strongly impacted by the water content. When the water content exceeds a critical value, the dynamic strength decreases with increasing water content. An opposite variation in dynamic strength with increasing water content is observed when the water content is less than the critical value.

(3) The dynamic strength is impacted by the clay content and clay mineral composition. The strength is correlated with the main clay mineral composition and decreases with the clay content.

(4) The dynamic cohesion is impacted by the clay mineral composition, water content, and cyclic failure time. Specifically, the dynamic cohesion of the mudded intercalations with illite is greater than that for mixed montmorillonite/illite but lower than that for kaolinite. Such cohesions initially increase slightly with water content and cyclic failure time but then decrease.

(5) The dynamic friction angle is strongly impacted by the water content. Specifically, as the water content rises, the dynamic friction angle decreases.

(6) The dynamic strength, cohesion, and friction angle of the mudded intercalations are smaller than those of loess, silt, clay, and common soils.

\section{Data Availability}

The data used to support the findings of this study are available from the corresponding author upon request.

\section{Conflicts of Interest}

The authors declare that there are no conflicts of interest regarding the publication of this article.

\section{Acknowledgments}

This research was financially supported by the National Natural Science Foundation of China (U1504523), the Key Research and Development Plan in Henan Province (182102210014), and the Open Foundation of Jiangxi Engineering Research
Centre of Water Engineering Safety and Resources Efficient Utilization (OF201602).

\section{References}

[1] S. Y. Xue and S. J. Wang, "Dynamic Triaxial test of the in-situ siltized intercalations in Xiaolangdi project," Chinese Journal of Geotechnical Engineering, vol. 19, pp. 89-94, 1997.

[2] W. P. Gong, Y. M. Tien, C. H. Juang, J. R. Martin, and J. Zhang, "Calibration of empirical models considering model fidelity and model robustness-focusing on predictions of liquefaction-induced settlements," Engineering Geology, vol. 203, pp. 168-177, 2016.

[3] D. Q. Li and E. T. Selig, "Cumulative plastic deformation for fine-grained subgrade soils," Journal of Geotechnical Engineering, vol. 122, no. 12, pp. 1006-1013, 1996.

[4] D. W. Li and J. H. Fan, "A study of mechanical property of artificial frozen clay under dynamic load," Advances in Civil Engineering, vol. 2018, Article ID 5392641, 8 pages, 2018.

[5] E. Cowgille, A. Yin, T. M. Harrison, and X. F. Wang, "Reconstruction of the Altyn Tagh fault based on U-Pb geochronology: role of back thrusts, mantle sutures, and heterogeneous crustal strength in forming the Tibetan plateau," Journal of Geophysical Research: Solid Earth, vol. 108, no. B7, pp. 457470, 2003.

[6] C. D. Li, J. Yan, J. F. Wu et al., "Determination of the embedded length of stabilizing piles in colluvial landslides with upper hard and lower weak bedrock based on the deformation control principle," Bulletin of Engineering Geology and the Environment, pp. 1-20, 2017.

[7] M. Hyodo, A. F. L. Hyde, Y. Yamamoto, and T. Fujii, "Cyclic shear strength of undisturbed and remoulded marine clays," Soils and Foundations, vol. 39, no. 2, pp. 45-58, 1999.

[8] Z. Liu, F. Liu, F. Y. Ma et al., "Collapsibility, composition and microstructure of loess in China," Canadian Geotechnical Journal, vol. 53, no. 4, pp. 673-686, 2015.

[9] Z. M. He and B. L. Wang, "Instability process model test for bedding rock slope with weak interlayer under different rainfall conditions," Advances in Civil Engineering, vol. 2018, Article ID 8201031, 8 pages, 2018.

[10] Y. X. Wang, P. P. Guo, W. X. Ren et al., "Laboratory investigation on strength characteristics of expansive soil treated with jute fiber reinforcement," International Journal of Geomechanics, vol. 17, no. 11, article 04017101, 2017.

[11] X. G. Wang, L. Huang, C. B. Yan, and B. Lian, "HKCV rheological constitutive model of mudstone under dry and saturated conditions," Advances in Civil Engineering, vol. 2018, Article ID 2621658, 10 pages, 2018.

[12] ASTM D5311/D5311m-13, Standard Test Method for Load Controlled Cyclic Triaxial Strength of Soil, ASTM International, West Conshohocken, PA, USA, 2013.

[13] J. Li, S. X. Chen, and L.-F. Jiang, "Test study on the influences of dynamic stress and load history to the dynamic properties of the remolded red clay," Earth Sciences Research Journal, vol. 20, no. 4, pp. 1-8, 2016.

[14] B. Paramasivam and S. Banerjee, "Factors affecting post-cyclic undrained shear strength of marine clay," Geotechnical and Geological Engineering, vol. 35, no. 4, pp. 1783-1791, 2017.

[15] V. Manmatharajan and S. Sivathayalan, "Effect of over consolidation on cyclic resistance correction factors Ko and Ka," in Proceedings of Fourteenth Pan-American Conference on Soil Mechanics and Geotechnical Engineering and the Sixty-Fourth Canadian Geotechnical Conference, Toronto, Canada, October 2011. 
[16] H. A. Rondón, T. Wichtmann, T. Triantafyllidis, and A. Lizcano, "Comparison of cyclic triaxial behavior of unbound granular material under constant and variable confining pressure," Journal of Transportation Engineering, vol. 135, no. 7, pp. 467-478, 2009.

[17] H. W. Zhang, Z. J. Wan, D. Ma, B. Zhang, and P. Zhou, "Coupled effects of moisture content and inherent clay minerals on the cohesive strength of remodelled coal," Energies, vol. 10, no. 8, pp. 1234-1241, 2017.

[18] T. C. Kenney, "The influence of mineral composition on the residual strength of natural soils," in Proceedings of Geotechnical Conference, Oslo, Norway, July 1967.

[19] S. Nakamura, S. Gibo, K. Egashira, and S. Kimura, "Platy layer silicate minerals for controlling residual strength in landslide soils of different origins and geology," Geology, vol. 38, no. 8, pp. 743-746, 2010.

[20] H. B. Seed, Representation of Irregular Stress Time Histories by Equivalent Uniform Stress Series in Liquefaction Analyses, University of California, California, CA, USA, 1975.

[21] F. Y. Tang and H. Y. Chi, "Dynamic triaxial test on Leizehu reservoir dam," Shandong Water Resources, vol. 16, pp. 40-41, 2015.

[22] J. W. Jiang, X. B. Rao, W. Zhang, J. J. Pan, and Z. B. Wang, "Experimental study on dynamic properties of saturated fine sand in Jingjiang levees," China Earthquake Engineering Journal, vol. 37, pp. 759-764, 2015.

[23] Y. Q. Tang, Y. L. Wang, Y. Huang et al., "Dynamic strength and dynamic stress-strain relation of silt soil under traffic loading," Journal-Tongji University, vol. 32, no. 6, pp. 701-704, 2004.

[24] C. P. Polito and J. R. Martin, "Effects of nonplastic fines on the liquefaction resistance of sands," Journal of Geotechnical and Geoenvironmental Engineering, vol. 127, no. 5, pp. 408-415, 2001.

[25] T. L. Youd, I. M. Idriss, R. D. Andrus et al., "Liquefaction resistance of soils: summary report from the 1996 NCEER and 1998 NCEER/NSF workshops on evaluation of liquefaction resistance of soils," Journal of Geotechnical and Geoenvironmental Engineering, vol. 127, no. 10, pp. 817-833, 2001.

[26] T. Hara, T. Kokusho, and R. Hiraoka, "Undrained strength of gravelly soils with different particle gradations," in Proceedings of 13th World Conference on Earthquake Engineering, Vancouver, BC, Canada, August 2004. 


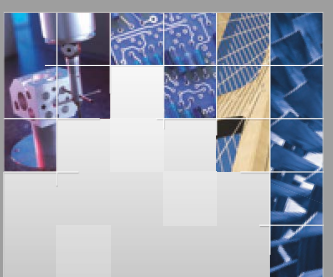

\section{Enfincering}
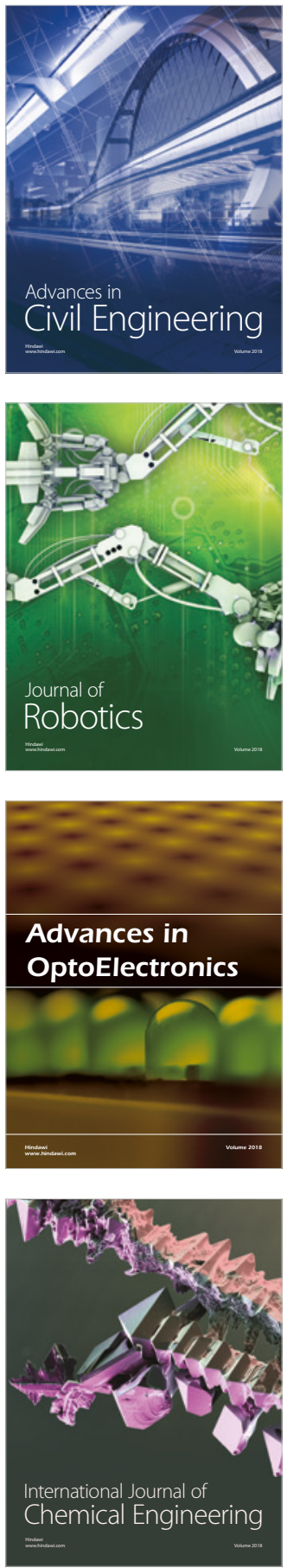

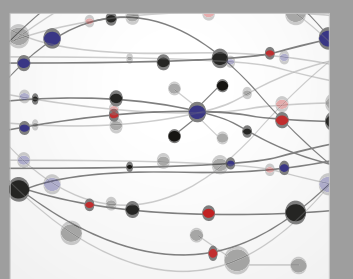

\section{Rotating \\ Machinery}

The Scientific World Journal

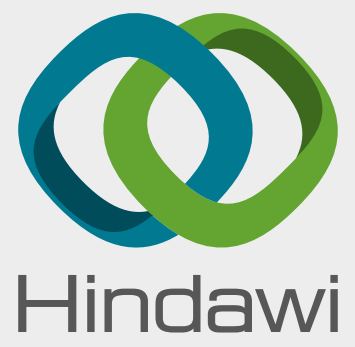

Submit your manuscripts at

www.hindawi.com
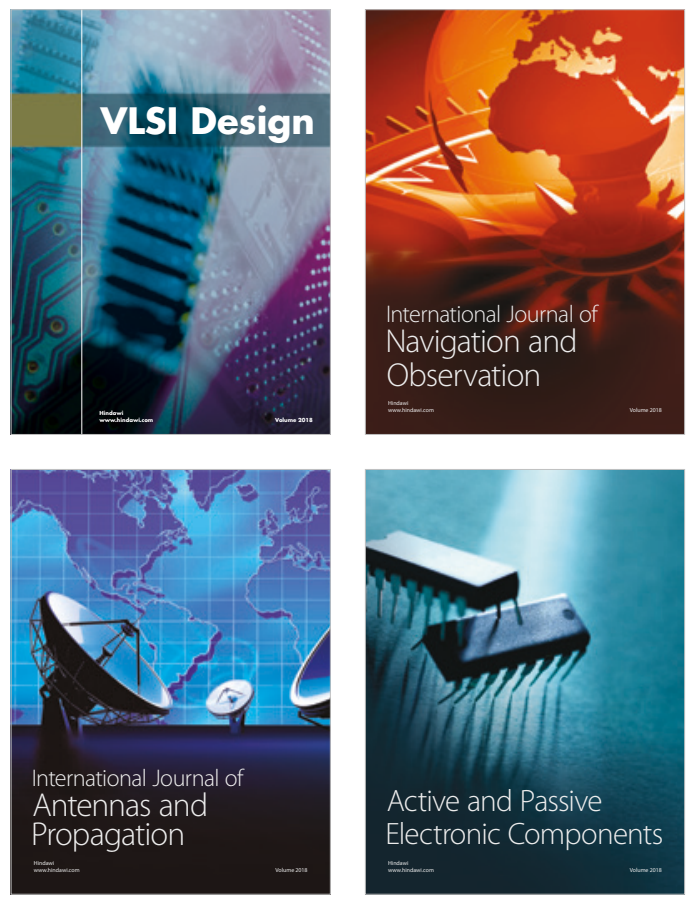
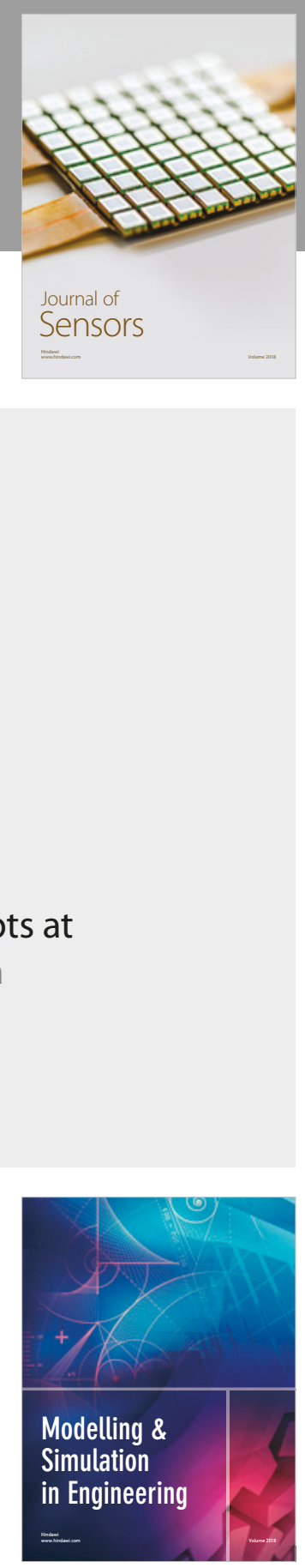

\section{Advances \\ Multimedia}
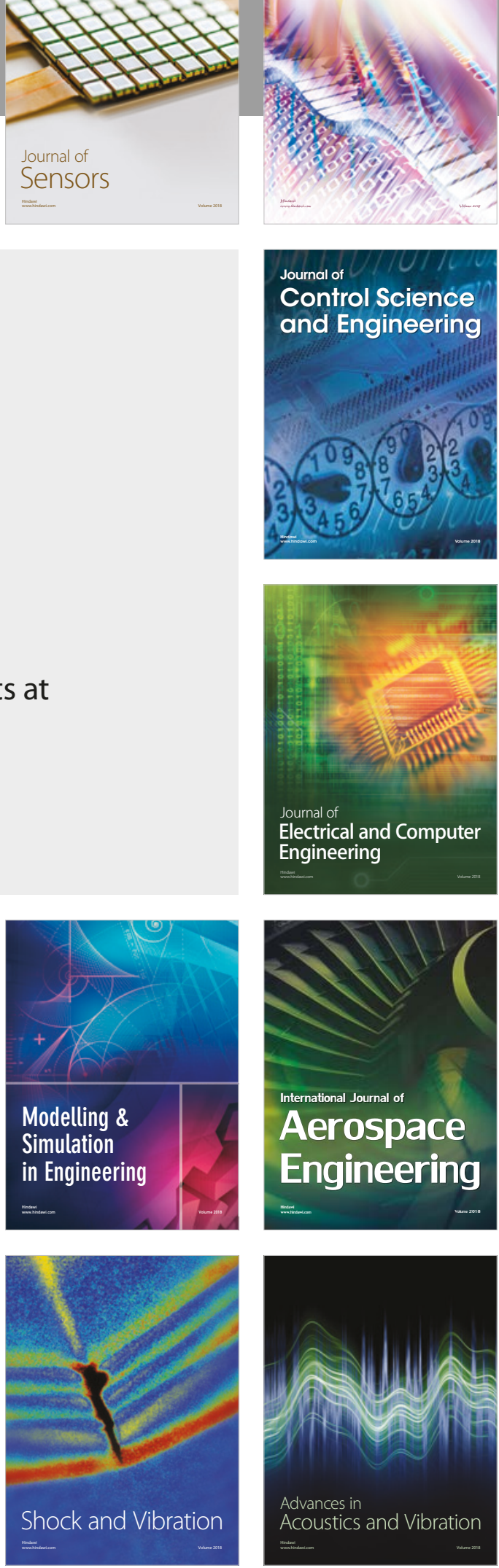